\title{
Undernutrition as Risk Factor of Hydrocephalus Prevalence in Children with Tuberculous Meningitis
}

\author{
John Patria Maruli Sinaga, ${ }^{1}$ Nelly Amalia Risan, ${ }^{2}$ Uni Gamayani ${ }^{3}$ \\ ${ }^{1}$ Faculty of Medicine Universitas Padjadjaran, ${ }^{2}$ Department of Child Health Faculty of Medicine \\ Universitas Padjadjaran/Dr. Hasan Sadikin General Hospital Bandung, ${ }^{3}$ Department of Neurology \\ Faculty of Medicine, Universitas Padjadjaran/Dr. Hasan Sadikin General Hospital Bandung
}

\begin{abstract}
Background: Hydrocephalus is the most frequent neurological complication in children with tuberculous meningitis. Tuberculosis infection cannot be separated from nutritional status. Children with undernutrition have decreased immunity thus could affect clinical manifestation of tuberculous meningitis. This study was conducted to identify the relationship between undernutrition and the prevalence of hydrocephalus in tuberculous meningitis.
\end{abstract}

Methods: An analytic observational study was carried out to 38 medical records of children with tuberculous meningitis in Dr. Hasan Sadikin General Hospital from 2007 to 2015. Variables that were studied included gender, age, advanced stage of disease, motoric paralysis, history of seizure, nutritional status and hydrocephalus. The collected data were analyzed using Chi-Square test.

Results: Out of 21 subjects with undernutrition, 11 subjects were found to have hydrocephalus. The analysis using chi-square was statistically significant $(\mathrm{p}=0.009)$. Prevalence ratio=4.45 (CI 95\% 1.14-45.43), meaning tuberculous meningitis children with undernutrition were at risk of hydrocephalus 4.45 times greater than children with normal nutritional status.

Conclusions: Undernutrition may increase the risk of hydrocephalus in children with tuberculous meningitis. [AMJ.2017;4(1):143-7]

Keywords: Hydrocephalus, nutritional status, tuberculousmeningitis, undernutrition

\section{Introduction}

Tuberculous meningitis is the most severe complication of tuberculosis infection and occurs in $5-10 \%$ of tuberculosis cases. ${ }^{1}$ There are 92 patients with tuberculous meningitis during the period 2000-2005 at Dr. Hasan Sadikin General Hospital, Bandung. ${ }^{2}$ The prevalence is higher than the prevalence in developed countries (United States) where there are only 34 cases of tuberculous meningitis in 11.5 years. ${ }^{1}$ Tuberculous meningitis is highly associated with mortality and long-term sequelae. A study reported that the most often neurological complication is hydrocephalus (42\%). ${ }^{3}$ Tuberculous meningitis patients with hydrocephalus after ventriculoperitoneal shunt has poor outcome: $42.1 \%$ died while the rest ranging from good outcome to moderate disability. ${ }^{4}$

Rautet et al. ${ }^{5}$ reported that predictor factors of hydrocephalus are advanced stage of disease, severe disability, duration of disease $>2$ months, seizures, impaired vision, papilledema, cranial nerve palsy ( $\mathrm{N} \mathrm{VI}$ ), hemiparesis, cerebrospinal fluid total cell count $>100 / \mathrm{mm}^{3}$, cerebrospinal fluid protein $>2.5 \mathrm{~g} / \mathrm{L}$. Tuberculous infections are always associated with nutritional status. Children with undernutrition have decreased immunity. Decreased immunity can affect course of tuberculous meningitis. In addition, weak immunity supports exudate formation in basilar area. ${ }^{3}$ This study was conducted to identify the impact of undernutrition to the insidence of hydrocephalus in children with tuberculous meningitis.

\section{Methods}

The method used was the unpaired comparative analytical with cross-sectional design. This research was conducted in inpatient ward

Correspondence: John Patria Maruli Sinaga, Faculty of Medicine, Universitas Padjadjaran, Jalan Raya BandungSumedang Km.21, Jatinangor, Sumedang, Indonesia, Phone: +62 8996087277 Email: johnpmsinaga@gmail.com 
of neuropediatric and neurosurgery of Dr. Hasan Sadikin General Hospital, Bandung during the period 2007-2015. After approval of the Health Research Ethics Committee of Dr. Hasan Sadikin General Hospital, Bandung, subjects of the study were determined by medical record review of children with tuberculous meningitis. The inclusion criteria were the diagnosis of tuberculous meningitis and the age range must be within 1-14 years. Meanwhile, the exclusion criteria were medical records that were not accompanied by weight and height data.

All medical records of the subject were analyzed and some information was recorded such as identity (name, age, sex), physical examination (weight, height, motoric paralysis), stage of disease, history of seizure and the result of lab investigation (CT scan).

Personal and clinical manifestation characteristics of the subject such as sex, age, advanced stage of disease, motoric paralysis, and history of seizure were inserted into the subject's characteristic table. Gender was categorized as boy and girl. The age of subjects was grouped into 2 : $<5$ years and $\geq 5$ years. Advanced stage of disease, motoric paralysis and history of seizure were categorized into two groups (yes and no) based on the presence of these variables on each subject.

The nutritional status was measured by 2 indicators: weight-for-length (weight/ length) was used for children aged $\leq 5$ years and Body Mass Index-for-age (BMI/age) was used for children aged $>5$ years. Weight, height and BMI were then converted into standard deviation score ( $\mathrm{z}$ score) using the World Health Organization (WHO) Anthro program. Several data such as age, weight and height were inserted into the program and the program automatically counted $\mathrm{z}$ score for each indicator.

The Z scores are categorized into the nutritional status according to the following criteria: Based on weight/length or BMI/age: 1) Normal ( $\mathrm{z}$ score $\geq-2$ to $\leq+1$ ) 2) Wasted ( $\mathrm{z}$ score $\geq-3$ to $<-2$ ) 3 . Severely wasted (z-score $<-3){ }^{6}$ The study population was divided into two groups based on nutritional status. The undernutrition group included children with wasted and severely wasted. While the normal nutrition group included children with normal range.

Sample size was determined by the formula for unpaired categorical comparative analysis with $\alpha=5 \%, \beta=20 \%$, value of $p 1=0.407$, $\mathrm{p} 2=0.307$ and $\mathrm{p} 1-\mathrm{p} 2=0.1$. From the calculation, the estimated minimum sample size (n) was

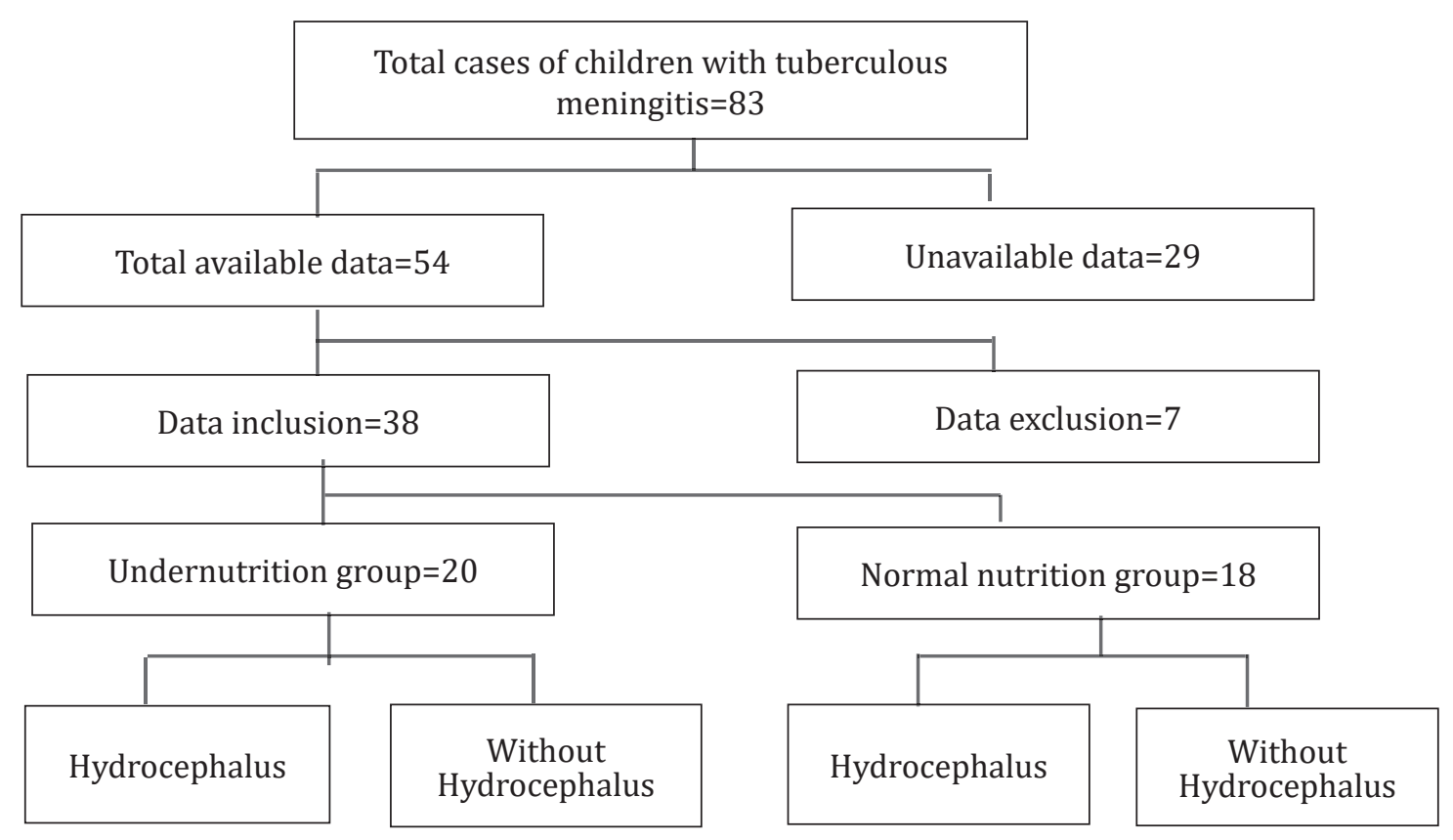

Figure 1 Data Collection and Selection 
Table 1 Subject and Clinical Manifestation Characteristics on Group with and without Hydrocephalus

\begin{tabular}{|c|c|c|c|c|}
\hline Characteristic & $\begin{array}{l}\text { Hydrocephalus } \\
\qquad(n=13)\end{array}$ & $\begin{array}{c}\text { Without } \\
\text { hydrocephalus } \\
\text { (n=25) }\end{array}$ & $p$ value & $\begin{array}{c}\text { Prevalence Ratio } \\
\text { (Confidence } \\
\text { Interval 95\%) } \\
\end{array}$ \\
\hline Gender & & & 0.728 & $1.31(0.49-3.48)$ \\
\hline Boys & 9 & 15 & & \\
\hline Girls & 4 & 10 & & \\
\hline Age & & & 0.575 & $1.29(0.52-3.24)$ \\
\hline$<5$ years old & 8 & 13 & & \\
\hline$\geq 5$ years old & 5 & 12 & & \\
\hline Advanced stage of disease & & & 0.004 & $4.12(1.34-12.63)$ \\
\hline Yes & 10 & 7 & & \\
\hline No & 3 & 18 & & \\
\hline Motoric paralysis & & & 0.263 & $1.75(0.75-4.106)$ \\
\hline Yes & 5 & 5 & & \\
\hline No & 8 & 20 & & \\
\hline History of seizure & & & 1.000 & $1.04(0.39-2.70)$ \\
\hline Yes & 9 & 17 & & \\
\hline No & 4 & 8 & & \\
\hline
\end{tabular}

19 subjects for each group, so the total sample $(2 \mathrm{n})$ was 38 subjects.

The medical record information system recorded 83 cases of children with tuberculous meningitis at Dr. Hasan Sadikin General Hospital, Bandung. Thirty eight data were taken as study subjects after fulfilling the inclusion criteria, this study had no exclusion criteria. After investigation, there were 20 subjects classified as undernutrition group and 18 subjects classified as normal nutrition group (Figure 1).

After performing several processes including recording, editing and coding, then data analysis was conducted using a computer statistical program. This study was analyzed by used of chi-square test. The result was significant if the $\mathrm{p}<0.05$.

\section{Results}

In this study, the number of boys was more than girls. Children with tuberculous meningitis were found more in the category of age less than 5 years. Additionally, hydrocephalus was found more in subjects with an advanced stage of disease. The advanced stage of disease showed significant association with hydrocephalus ( $p$ value $=0.004$ ) thus further analysis was needed. Motoric paralysis and history of seizure did not show statistically significant results (Table 1).

Table 2 Relationship between Nutritional Status of Tuberculous Meningitis Children Patients and Number of Hydrocephalus Cases

\begin{tabular}{lcccc}
\hline Nutritional Status & Hydrocephalus & $\begin{array}{c}\text { Without } \\
\text { hydrocephalus }\end{array}$ & p value & $\begin{array}{c}\text { Prevalence Ratio } \\
\text { (Confidence } \\
\text { Interval 95\%) }\end{array}$ \\
\hline Undernutrition & 11 & 10 & 0.009 & $4.45(1.14-45.43)$ \\
Normal nutrition & 2 & 15 & & \\
\hline
\end{tabular}


The number of hydrocephalus cases were higher in the undernutrition group (11 subjects) compared to the normal nutrition group (2 subjects). The prevalence of hydrocephalus in the undernutrition group was $52.4 \%$, while the prevalence of hydrocephalus in the normal nutrition group was $11.8 \%$. The analysis is statistically significant with $\mathrm{p}$ value $=0.009(\mathrm{PR}=4.45$, CI 95\% 1.14-45.43) (Table 2).

The statistical analysis test between nutritional status and hydrocephalus based on the advanced stage of disease resulted in $\mathrm{p}=0.003$ (PR=9, CI 95\% 1.32-61.24). These results indicated that the advanced stage of disease was a confounding variable.

\section{Discussion}

The comparison of numbers of subjects by sex was not equal, namely 1.42:1. Although the number of boys was larger, there was no significant association between sex and hydrocephalus in the statistical analysis with $\mathrm{p}=0.728$. These results were consistent with a study of van Well et al. $^{7}$ that reports the dominance of boys and there is no statistical significance.

In this study, there were more subjects with age less than five years old. This result was consistent with several previous studies conducted by Nelly Amalia and Heda Melinda ${ }^{2}$, van Well et al. ${ }^{7}$, Rock RB et al. ${ }^{8}$ But there was no significance for age $(p=0.575)$. The course disease of tuberculous meningitis was faster in children than adults. Clinical manifestation could be different if accompanied by a factor resulting in immunodeficiency state such as undernutrition which is the focus of this study. ${ }^{9-11}$

Furthermore, some clinical conditions of subjects were analyzed in conjunction with hydrocephalus, such as the advanced stage of disease, motoric paralysis and history of seizure. But only the advanced stage of disease was found to be significant. These results were in contrast to the study reported by Raut et al. ${ }^{5}$ in which these three variables are the predictors of hydrocephalus. Moreover, this study was in line with the study of Anderson et $\mathrm{al}^{3}{ }^{3}$ which found seizure and motoric paralysis only occurred in $28 \%$ and $5 \%$ of subjects and were not statistically significant. In this study and a study of Anderson et al. ${ }^{3}$, motoric paralysis and history of seizure were assessed from hospital medical records. Information on medical records can be erroneously recorded resulting in information bias.
This was in contrast to Raut's $\mathrm{s}^{5}$ study which used prospective cohort with better level of evidence based medicine. Information bias could be the reason why these two conditions were not related to hydrocephalus in this study. At an advanced stage of disease, bloodbrain barrier permeability will continue to rise, causing exudate formation which then causes hydrocephalus, whether communicant or non-communicant. ${ }^{8}$ Cherian and Thomas ${ }^{12}$ also reported that the stage of tuberculous meningitis is the most important factor for assessing prognosis.

Prevalence of hydrocephalus in children with undernutrition was higher than in children with normal nutrition. Tuberculous meningitis children with undernutrition are at risk of hydrocephalus 4.45 times greater than children with normal nutritional status. Currently, there is no study about relationship of nutritional status with hydrocephalus specifically. However, this result was supported by a study of Cherian and Thomas ${ }^{12}$ which reported undernutrition as the determinant factor of outcome and prognosis patients with tuberculous meningitis.

Moreover, protein deficiency causes activation of the hypothalamic-pituitaryadrenal axis resulting in increased serum glucocorticoid hormones. High glucocorticoid causes thymocyte cell atrophy (particularly immature CD4+ and CD8+ immature cells), thereby reducing cell proliferation of $\mathrm{T}$ lymphocytes. Besides, undernutrition also causes changes of $\mathrm{Fc}$ receptors found on $\mathrm{T}$ lymphocytes so that the function of these cells in marking antigen of Mycobacterium tuberculosis is disrupted. Tuberculosis infection will continue to get worse, while the body's defenses become weak because of undernutrition. This will affect the clinical manifestation of tuberculous meningitis. ${ }^{9,11}$

The advanced stage of disease statistically significant affected the relationship between undernutrition and prevalence of hydrocephalus. Tuberculous meningitis children with undernutrition and advanced stage of disease have 9 times greater risk to hydrocephalus than children with mild and moderate stage. Anderson et $\mathrm{al}^{3}{ }^{3}$ reported an advanced stage of disease is significant to the incidence of stroke with $\mathrm{p}$ value $<0.001$. Furthermore, a group of subjects with stroke reported having a higher risk of hydrocephalus. That study showed association among advanced stage of disease, stroke, and hydrocephalus in patients with tuberculous meningitis. 
Additionally, a tuberculous meningitis patient with early stage usually has good outcome and will deteriorate with increasing stage of disease. While a patient with advanced stage of disease has poor outcome, almost $50 \%$ died while the rest suffered permanent sequelae such as blindness, deafness, paraplegia, diabetes insipidus, seizures and mental retardation. Delayed milestone development in children can occur that later will result in cognition and emotional disorders. ${ }^{3,12}$

From this study, it can be concluded that undernutrition in children with tuberculous meningitis increases the risk of hydrocephalus. Advanced stage of disease is also designated as confounding factor associated with hydrocephalus. This study has some limitations such as the limited number of samples since it has used medical records as secondary data. Hospital medical records are generally limited to the last 5-year data, which was 2010-2015. This study uses data from the period 2007-2015 so there are medical records that cannot be taken as study subjects. Moreover, because using secondary data, the available information is limited to those recorded in the medical record. Several conditions are potential to be confounding variables in this study but cannot be analyzed due to absence of information such as the duration of tuberculosis disease, history of chronic disease (congenital heart disease, asthma, HIV/AIDS) and drop-out treatment of tuberculosis.

Thus, the theoretical suggestion of this study is to perform a study similar to this model but with more number of subjects. The practical suggestion from this study is health institutions and health care providers should improve interventions to unresolved children nutritional issues in Indonesia to prevent hydrocephalus in children with tuberculous meningitis as early as possible. If hydrocephalus can be prevented by improving the nutritional status, the possibility of poor outcome on Indonesian children can be prevented as well.

\section{References}

1. Galimi R. Extrapulmonary tuberculosis: tuberculous meningitis new developments. Eur Rev Med Pharmacol
Sci. 2011;15(4):365-86.

2. Nelly Amalia Risan, Heda Melinda Nataprawira. Hydrocephalus as a complication of pediatric tuberculous meningitis: clinical features and outcome. MKB. 2005;37(1):13-20.

3. Anderson N, Somaratne J, Mason D, Holland D, Thomas M. Neurological and systemic complications of tuberculous meningitis and its treatment at Auckland City Hospital, New Zealand. J Clin Neurosci. 2010;17(9):1114-8.

4. Rajshekhar V. Management of hydrocephalus in patients with tuberculous meningitis. Neurol India. 2009;57(4):368-74.

5. Raut T, Garg RK, Jain A, Verma R, Singh MK, Malhotra HS, et al. Hydrocephalus in tuberculous meningitis: incidence, its predictive factors and impact on the prognosis. J Infect. 2013;66(4):330-7.

6. WHO. WHO Child Growth Standards. Switzerland: Department of Nutrition for Health and Development WHO; 2006 [cited 201515 Mei]. Available from: http://www.who.int.

7. van Well GT, Paes BF, Terwee CB, Springer P, Roord JJ, Donald PR, et al. Twenty years of pediatric tuberculous meningitis: a retrospective cohort study in the western cape of South Africa. Pediatrics. 2009;123(1):e1-8.

8. Rock RB, Olin M, Baker CA, Molitor TW, Peterson PK. Central nervous system tuberculosis: pathogenesis and clinical aspects. Clin Microbiol Rev. 2008;21(2):243-61.

9. Cunningham-Rundles S, McNeeley DF, Moon A. Mechanisms of nutrient modulation of the immune response. J Allergy. 2005;115(6):1119-28.

10. Hughes S, Kelly P. Interactions of malnutrition and immune impairment, with specific reference to immunity against parasites. Parasite Immunol. 2006;28(11):577-88.

11. Savino W, Dardenne M, Velloso LA, Dayse Silva-Barbosa $\mathrm{S}$. The thymus is a common target in malnutrition and infection. $\mathrm{Br} \mathrm{J}$ Nutr. 2007;(98 Suppl 1):S11-6.

12. Cherian A, Thomas S. Central nervous system tuberculosis. Afr Health Sci. 2011;11(1):116-27. 